\title{
MINHA CASA MINHA VIDA - ENTIDADES: \\ Novos arranjos para a operaçáo da política habitacional no Brasil
}

\section{Camila Moreno de Camargo}

https://orcid.org/0000-0002-9142-2334

Instituto de Arquitetura e Urbanismo da Universidade de São Paulo (IAU-USP), São Carlos - SP, Brasil. E-mail: cmcamargo@usp.br DOI: $10.1590 / 3510219 / 2020$

\section{Minha Casa Minha Vida Entidades e a financeirização da moradia}

Parte dos estudos recentes sobre os processos contemporâneos de acumulação revelam as relações de tensão que podem ser matizadas pela polêmica em torno da dominância financeira ou financeirização, como fenômeno marcado por um conjunto de especificidades associadas a uma racionalidade neoliberal (Paulani, 2017) e como marca de um conjunto de relaçóes e modos de intervenção urbana (Fix, 2007; Rolnik, 2015). Por esta chave, é possível entrever os nexos que tais processos estabelecem com novas modulações relacionadas às práticas vinculadas ao Estado, com novas conformaçôes sociais e territoriais, e com dispositivos e processos de subjetivação emaranhados às transformaçóes nos

Artigo recebido em: 21/09/2018

Aprovado em: 18/10/2019 modos de representar e figurar as matrizes da desigualdade social e urbana, que parecem caracterizar a cidade contemporânea e nos colocar novas questôes de investigação.

Do ponto de vista da financeirização do circuito imobiliário, uma bibliografia já extensa destaca o "alinhamento inédito entre legislação, instituiçóes públicas, recursos financeiros e cadeia produtiva da construção" (Shimbo, 2016, p.119). Segundo esta autora, o principal produto de tal alinhamento é a "habitação social de mercado", que designa, como categoria mais ampla e a partir de uma fronteira de indistinção, uma forma de produção de habitação localizada em uma zona intermediária híbrida, entre a produção pública de habitação de interesse social e a produção privada de habitação para o mercado, sobretudo via capital financeiro".

A redefinição dos vínculos entre agentes, processos e estruturas em diferentes escalas, e a miríade de mercado articulada à dispersão territorial dessa 
produção habitacional, ajudam a reconhecer a penetração de práticas financeirizadas em atividades econômicas e sociais que ultrapassam a esfera financeira e atravessam a produção do espaço urbano, residindo nas interaçóes que envolvem a terra, a face mais cruel desse processo (Sanfelici, 2013).

$\mathrm{Na}$ esteira dessas novas interaçôes, destaca-se o programa Minha Casa Minha Vida (MCMV) como política anticíclica de emprego, de estratégia bem-sucedida e de perfil distributivista, através do qual o governo pretendia direcionar, pela concentração de recursos e mecanismos de proteção ao financiamento, o deslocamento de atuação do mercado imobiliário para as faixas de renda mais baixa. Baseado em uma produção por oferta, e não por demanda, apostou na iniciativa privada como agente motora desse processo, subordinando as leis urbanísticas à produção direta promovida por empresas construtoras, para as quais foi destinada a maioria absoluta dos recursos (subprograma MCMV Construtoras).

Se a "marca" atribuída ao programa MCMV pode ser caracterizada pelos aspectos produtivos, construtivos e de inserção urbana, que constituem a habitação social de mercado, por outros aspectos a serem destacados neste artigo, a provisão habitacional vinculada a esse "pacote-programa" se insere no conjunto de contradiçôes que configuram o Brasil lulista, e trazem outras conotaçóes ao sentido de marca que lhe foi atribuído. Por um lado, o incremento notável de recursos investidos - desde o lançamento do programa até a iminência do lançamento de sua terceira fase -, propiciou a construção de mais de quatro milhóes de novas moradias para os brasileiros, com subsídios quase integrais para as famílias com renda mais baixa, distribuídas por todo o território e revelando melhorias reais nos modos de morar (mas não de viver) dessa parcela mais pobre da população. Por outro lado - sustentando o setor imobiliário e lhe conferindo poderes decisórios, que praticamente anulam o papel das prefeituras, que ficam com o ônus de um programa descolado de uma política urbana e fundiária -, o programa aprofunda, de modo bastante complexo, as questóes presentes nas periferias das cidades brasileiras.

É parte dessa engrenagem a modalidade "Entidades" (MCMV Entidades) ${ }^{1}$, que se apresenta bas- tante emblemática, pois através de sua análise será possível flagrar vínculos complexos - com consequências nada desprezíveis para o rearranjo do campo de forças entre movimentos de moradia e reforma urbana, o Estado e o mercado imobiliário -, na operação de um novo diagrama de relaçóes entre produção de moradia e luta pela apropriação da cidade (ou seu avesso) (Rizek, Santo Amore, \& Camargo, 2014).

O programa MCMV Entidades funciona por meio da concessão de financiamentos a beneficiários organizados de forma associativa por uma Entidade Organizadora (associaçóes, cooperativas, sindicatos e outros), com recursos provenientes de fundos públicos. O mesmo pode ter contrapartida complementar de estados e dos municípios, por intermédio do aporte de recursos financeiros, bens e/ou serviços economicamente mensuráveis, necessários à composição do investimento realizado, ou pelas próprias famílias que compóem a demanda do empreendimento. $\mathrm{Na}$ faixa de atendimento em que se insere este programa, a moradia é quase que integralmente subsidiada, e a parcela mensal paga pela família beneficiária é determinada pela sua capacidade de pagamento.

O MCMV Entidades também se diferencia pela possibilidade de se estabelecer um contrato preliminar específico para a compra do terreno e pagamento antecipado dos projetos. Essa é uma "vantagem competitiva" dada às entidades nas disputas por terra, em um mercado bastante aquecido pelo próprio MCMV, permitindo que os proprietários recebam os valores relativos ao terreno, tão logo se efetive a viabilidade técnica e financeira do empreendimento. No contrato da obra, depois de apresentados os licenciamentos, projetos executivos, orçamentos e aprovaçóes necessárias, as dimensóes de administração adquirem outra especificidade, que leva em conta a natureza sem fins lucrativos das associaçóes e a consequente inexistência do capital de giro. A execução das obras ocorre com a antecipação de até duas parcelas dos recursos, revertendo-se em boas condiçóes de negociação nas compras e contrataçóes pelas entidades.

Nesta modalidade Entidades, coloca-se a autogestáo habitacional (ou seu discurso), e em outro patamar, onde as associaçóes, cooperativas e outras 
entidades sociais podem se posicionar como atores diretos da produçáo: selecionando e organizando as famílias, contratando diretamente os projetos e discutindo-os com os futuros "beneficiários", assumindo a responsabilidade pela gestão da obra, seja por meio da contratação de construtoras, seja pela compra de materiais e mão de obra em empreitadas, seja pela participação direta das famílias nas obras, com trabalho em mutirão.

Do ponto de vista de sua distribuição no território, a produção do MCMV Entidades aparece ancorada às porçóes do território inseridas em dinâmicas metropolitanas, onde a mobilização social já apresenta alguma trajetória anterior e onde se concentra a demanda por moradias dignas. Assim, por hipótese, pode-se aventar que essa modalidade mais diretamente se relaciona à imensa maioria do déficit habitacional no Brasil.

Esses processos, tão ricos quanto complexos, poderiam representar uma "cunha" no contexto geral do MCMV. No entanto, são variadas as dimensóes que envolvem sua implementação no território, e que se colocam como reflexão necessária a se detectar e compreender os múltiplos sentidos das práticas que se articulam aos dispositivos operacionais do programa, assim como seus deslizamentos recentes.

Dessa perspectiva, para os apontamentos organizados a respeito dos processos que envolvem a produção da referida modalidade, o artigo pretende, como estrutura analítica, em primeiro plano, relacionar o programa MCMV Entidades com o contexto de formulação e implementação de políticas sociais recentes no Brasil, a partir de um campo de discussão mais amplo que dá relevo a modos de circulação de proposiçóes e práticas em outro âmbito; e, em segundo plano, discutir questôes construídas sobre determinados dispositivos operacionais do programa em tela, a partir, sobretudo da pesquisa exploratória e etnográfica em três conjuntos habitacionais localizados na Regiâo Metropolitana de São Paulo, a saber: I) Sonho Meu, no município de Mauá-SP; II) João Cândido A e B, localizados em Taboão da Serra-SP; e III) Florestan Fernandes e José Maria Amaral, que constituem único produto imobiliário em construção no bairro Cidade Tiradentes, em São Paulo-SP.

\section{O MCMV Entidades como face habitacional das políticas sociais do Brasil recente}

Algumas análises sobre a modalidade Entidades do programa MCMV apontam para questóes importantes inscritas em um contexto de contradiçóes onde se combinam um conjunto de programas e políticas sociais com a presença de formas de identificação e assinação da pobreza bastante específicas. Também sugerem que as práticas de mercado que o programa ativa e aos quais também se submete, aproximam-no do processo de empresariamento e financeirização da moradia e da cidade em curso no país, de modo bastante perverso, uma vez que implica na reconfiguração da atuação dos movimentos de moradia e na redução de uma agenda política ampla relacionada à reforma urbana, à operação do programa, apontando para novos padróes de governança presentes no território (Camargo, 2016).

Apesar de se tratar de uma produção ínfima em termos quantitativos ${ }^{2}$, se comparada a toda produção do programa $\mathrm{MCMV}$, a presença da modalidade Entidades tem uma dimensão política paradigmática, apoiando-se na tradição de políticas habitacionais autogestionárias, envolvendo os mais representativos movimentos de luta por moradia e reforma urbana do Brasil. Inscreve-se, por este ângulo, em um percurso histórico em torno de um programa federal que disponibilizasse recursos, e fosse estruturado a partir das práticas de autogestão, com um conjunto de questóes formuladas em dois momentos de debates que envolveram sua prática: o primeiro, nas décadas 1970-80, em que várias pesquisas construíam novas formas de representação da cidade periférica, concomitante à emergência dos movimentos sociais que se consolidavam a partir das influências de uma vertente libertária da igreja católica e de um conjunto de experiências em curso em outros países da América Latina, que envolviam práticas de mutirão e ajuda mútua, vinculadas à produção de moradia; e o segundo, de avaliação das experiências emblemáticas de produção habitacional através de procedimentos autogestionários desenvolvidas, sobretudo entre as décadas 1980-90, em São Paulo.

O programa apresenta uma rede de relações, a qual foi estabelecida a partir de novas formas as- 
sociativas (Camargo, 2013), onde se embaralham entidades distintas oriundas dos movimentos sociais, e instituiçóes que se conformam como organizaçóes sociais em um campo que abrange desde organizaçóes religiosas e assistenciais até fundações de origem empresarial. É importante notar que algumas dessas entidades contempladas e constituídas como participantes do programa reconverteram suas atividades a partir de outros setores de atuaçáo bastante diversos, objetivando operar como "máquinas de produção de casas” (Camargo, 2013), construir a demanda e organizá-la a partir de uma trama de sociabilidade muito frequentemente privada (família, vizinhança, conhecidos), para além de qualquer vínculo político ou politizante (Rizek, Santo Amore, \& Camargo, 2015).

Destacam-se ainda, nesse cenário, os "novos" movimentos, criados na transição da década de 1990 para 2000 , de atuação territorial ${ }^{3}$, que incorporarão o direito à moradia, mas não tanto os princípios da autogestão, a uma agenda mais ampla que articula temas relacionados aos territórios periféricos. Contudo, diante dos recursos do MCMV, mesmo esses movimentos não escaparão à lógica de incorporaçáo no e pelo mercado.

Nesse contexto, lançando mão de um espectro mais amplo da autogestão habitacional recente, onde se revelam formas associativas e atuações diversas, "deslizando ora mais à direita, ora mais ao centro, ora mais à esquerda”, o MCMV Entidades apresenta-se bastante emblemático. Isto porque cruza a produção do espaço urbano e da moradia com consequências perversas para o processo de consolidação e expansão de novas fronteiras periféricas, em um contexto de novas precariedades e formas de pobreza, bem como velhos e novos modos de enquadrá-las, geri-las e acomodá-las na dobra entre programas e políticas sociais.

Ainda assim, embora em pequena escala e com grandes dificuldades para operar um programa desenhado para construtoras, os movimentos sociais obtiveram ganhos relevantes com o MCMV, no sentido de atender às suas bases. Se, por um lado, os movimentos continuam a não participar efetivamente dos processos decisórios da política habitacional, por outro eles foram incluídos na lista de atores contemplados com a distribuição dos bene- fícios dos investimentos na área. Passaram a integrar o jogo do controle da distribuição dos ativos políticos do governo, juntamente com lideranças e grupos partidários que compóem sua base (Rolnik, 2015; Tatagiba \& Teixeira, 2014).

$\mathrm{Na}$ chave interpretativa dos "efeitos combinados”, Tatagiba e Teixeira (2014) destacam que a atuação dos movimentos sociais se estabelece em torno de dois pontos: o contexto e as interaçóes. Por contexto, entendem-se as características mais formais (estrutura e capacidade de resposta do Estado, ambiente institucional, nível das garantias democráticas) ou informais (correlações de forças, alinhamentos políticos, divisóes entre as elites) do ambiente no qual os movimentos atuam, que ampliam ou restringem suas chances potenciais de sucesso. Por interações, entende-se a relação que o movimento estabelece com apoiadores e antagonistas, dentro e fora do Estado, que moldam suas demandas, estratégias e a forma como avaliam os resultados de suas ações.

A capacidade de resistência dos movimentos sociais, as elaboraçóes sobre o tema da autonomia e de novas relaçóes sociais não orientadas pelo mercado, por um lado aproximam-nos de uma abordagem que critica veementemente a ressignificação das lutas pelas políticas públicas que buscam a construçâo e produção de consensos, onde se confundem sujeitos políticos e identidades reguladas (Harvey, 2014). Tais questôes ancoram-se também, por outro lado, em teorias que enfatizam os processos de institucionalização das açóes coletivas e que destacam a despolitizaçấo como elemento do próprio jogo democrático, por meio da qual a participação torna-se um problema de governança, de regulação de conflitos e gestão de pessoas, e não um foco para a mudança social (Tarrow, 2009).

Em outra escala de interaçóes, destaca-se a produção habitacional resultante das articulaçóes de movimentos sociais de moradia e entidades distintas organizados em redes latino-americanas. Essas redes atuam, sobretudo, na identificação, documentação e difusão de uma determinada produção habitacional que, em tese, sustenta-se em práticas autogestionárias e gestão social, por meio de encontros, oficinas, fóruns, publicaçóes e plataformas digitais, através de um sem número de apoios finan- 
ceiros para construção de estratégias de incidência. Dessa forma, dão conta de uma teia bastante emaranhada de relaçóes envolvendo os movimentos sociais de moradia, Estado e mercado, em significativos níveis financeirizados.

Por este recorte, seria possível entrever um campo tecido pela circulação de proposiçóes e práticas implementadas por agências multilaterais e organizaçóes internacionais, em um quadro de novas formulaçóes em torno do tema da governança, sobretudo no contexto latino-americano, e que dão conta deste continente e de suas populaçóes mais empobrecidas como laboratório de políticas públicas (Maranhão, 2010). Por esta lente, parece igualmente relevante analisar esse campo tecido pela circulação de ideias no âmbito mais amplo de formulação das políticas públicas habitacionais latino-americanas, que tanto impulsionaram a produção da "habitação social de mercado" predominante. É uma produção habitacional que está vinculada ao mercado financeirizado, como a "produção outra", em tela, não como formas opostas ou antagônicas, mas imbricadas em um mesmo processo de financeirização da cidade e das políticas públicas.

Em outros termos, no âmbito da invenção, multiplicação e popularização das políticas de transferência de renda, na América Latina, a instauração de uma hegemonia consensual será apontada por Lautier (2009), para quem a passagem da década de 1990 para 2000 implica na "criação de uma categoria, os pobres, que sáo tanto mais legitimamente os objetos de auxilio que se lhes atribuem, quanto mais se tem em conta que é esse auxilio que os cria". "Para este autor, a implantação de uma série de políticas "focalizadas" elimina uma noção "forte" - a dos direitos sociais - em benefício de uma noção "vazia", que opera a despolitização da questão social e deixa a "tensão subsistir apenas por sua contenção".

Para Lautier, as políticas "ultra-focalizadas" foram aquelas desenvolvidas ao longo dos anos 1990, a partir de uma categoria precisa, inseridas em duas dimensóes: a primeira, de ordem "técnica", que determina os alvos prioritários de auxílio, através de uma "visibilidade" seletiva que carrega forte peso ideológico e político; a segunda, imediatamente "política", trata da questão da eficácia em despolitizar a questão da pobreza, a partir da disjunção de dois problemas - o problema da ajuda aos pobres e o problema da luta contra a pobreza. As críticas das políticas "ultra-focalizadas" conduziram a uma mudança de "tática de governo dos pobres" em vários países latino-americanos, no final dos anos 1990 e início dos anos 2000, passando para o desenvolvimento de políticas "focalizadas", a partir de categorias mais amplas. Para o autor,

[...] essas críticas, todavia, não levaram a um questionamento da estratégia fundada sobre o tríptico moralização/tecnicização/ despolitização da questáo da pobreza, mas conduziram a uma mudança profunda dos encaminhamentos práticos das políticas públicas dessa luta, assim como a um ponto de inflexão: a substituição da "luta contra a pobreza" pela "luta contra a vulnerabilidade”. (Lautier, 2009)

Na mesma direção, Paoli (2007) destaca que a intervenção focalizada a partir do "fatiamento dos problemas" é útil em mais de um sentido, pois torna as coisas manejáveis e controladas, e cria um ciclo de procedimentos de atenção pública que gera uma nova relaçáo dos pobres com o Estado, "baseada na benevolência e não na reconstituição de direitos, o que reforça o sentido privado do ciclo predominantemente técnico do modelo" (Paoli, 2007, p. 247). Além disso, para a autora, a vinculação de reivindicações, diálogos e negociações ao funcionamento de "imperativos" econômicos requer o gerenciamento prático da escassez, o pragmatismo seletivo das decisóes realistas sobre as carências a serem resolvidas e o controle da própria negociação, os quais, obrigatoriamente, devem assumir uma cara moderna, democrática e pedagógica, ou seja, "participativa".

Em termos mais amplos, esta chave de interpretação aproxima o conjunto de questóes que envolvem o programa da ideia de "políticas de quantificação", sob a qual se entrevê a penetração de técnicas gerenciais que parametrizam a gestão de determinados setores públicos e que "governam a vida cotidiana" (Bardet, 2015, p. 9), embaralhando as noçóes de público e privado. Avançando por este caminho analítico que ilumina a construção e implementação dos dispositivos operacionais que 
sustentam as políticas sociais, somam-se os grandes indicadores de eficiência, em outro nível, e a produção de dados que permeia a própria produçáo e manutenção de políticas e programas públicos como forma de construção de objetos que possam ser administrados (Bardet, 2015).

Nesse quadro, e considerando o programa MCMV Entidades, iluminam-se duas questóes: a primeira, referente às ressignificaçóes e reconfiguraçóes nos modos de atuação dos movimentos de moradia, na perspectiva de uma determinada aglutinação ou aparente unidade em torno da modalidade em tela; a segunda, relacionada aos imbricamentos da produção habitacional (e urbana) resultante dessa articulação dos movimentos de moradia e de seus princípios orientadores - a autogestão, a propriedade coletiva e o mutirão - e de sua inserção em um contexto político recente onde, também na escala da América Latina, em um primeiro momento, partidos políticos progressistas assumiram os governos em nível federal e ensaiaram a implementação de políticas sociais que focalizavam, de modo bastante específico, o grande contingente de pobres em "exclusão". Em um segundo momento, já se observa um conjunto de formas mais amplas e complexas de resistências relacionadas à aparente retomada de uma agenda em direção ao direito à cidade e à moradia, e de contra-ataque a uma série de reformas bastante atreladas ao desmonte e perda de "direitos" por parte de governos resultantes de golpes políticos e midiáticos.

Dessa perspectiva, os conteúdos que estruturam o programa - e, em menor medida, a autogestáo -, aparecem neste contexto recente, e de modo mais significativo, em disputa. Trata-se de conteúdos vinculados à ideia de fabricação de determinado consenso em torno da proximidade dos movimentos sociais de moradia e dos governos petistas que o implementaram. Assim, diante do desmonte de políticas públicas, sobretudo no campo urbano e social, as questóes localizadas na articulação entre os níveis de concepção do MCMV Entidades, dos agenciamentos em torno de sua operacionalização e de sua implementação no território, estabelecem fortes nexos com o contexto globalizado de operacionalização e financeirização de políticas públicas, e imputam aos movimentos de moradia um "agir por fora e por dentro" do programa.

\section{Aproximaçóes possíveis a partir de dispositivos operacionais do programa em tela}

Para os apontamentos organizados neste artigo a respeito dos processos que envolvem a produção dessa modalidade, utilizamo-nos das questôes construídas a partir, sobretudo da pesquisa exploratória e etnográfica em três conjuntos habitacionais localizados na região metropolitana de São Paulo, procurando dar relevo a determinados aspectos que mais diretamente se relacionam aos dispositivos operacionais destacados, a saber: I) o sistema de credenciamento e habilitação das entidades, a partir do qual se entreveem as estratégias de atuação lançadas e as modulaçóes que reconfiguram a trajetória das entidades responsáveis pelos contratos de construção de moradia, como condiçáo à operação do programa; II) o sistema de credenciamento das famílias beneficiárias, onde se destacam os modos de composição ou "produção" da demanda e os critérios internos às entidades para acesso ou permanência no grupo de demanda, que envolverão esquema de pontuação e controle de presença em atividades que combinam desde o mutirão à participação em atos, caravanas, ocupações, dentre outras formas de mobilização, além do pagamento de contrapartidas financeiras mais ou menos visíveis; e III) o sistema de contrapartidas financeiras, por onde se entrevê um conjunto de "conquistas" negociadas e excepcionalizadas que marcará, em definitivo, o programa MCMV Entidades como política que se faz entre a noção de direito, a urgência e os negócios.

A título de breve apresentação dos conjuntos habitacionais onde se deu o campo de pesquisa, cabe informar que o conjunto "Sonho Meu", construído - mas não entregue por problemas financeiros que impediram a obra de ser totalmente concluída e legalizada -, em regime misto (alternando-se a administração direta e a empreitada global em determinadas fases da obra) no município de Mauá-SP, totaliza 200 unidades habitacionais organizadas em 7 torres de 7 pavimentos cada. O empreendimento foi organizado pela AMOVA (Associação do Movimento de Alfabetização de Jovens e Adultos), entidade que atua em vários programas de incentivo à produção habitacional. 
A partir das experiências no Programa Crédito Solidário (PCS), a entidade, cuja origem é o trabalho com alfabetização de jovens e adultos, passou a atuar, a partir de 2009, em vários programas de produção habitacional de interesse social, principalmente nos estados de São Paulo e Bahia, o que lhe conferiu o prêmio "Melhores Práticas em Gestão Local da Caixa Econômica Federal (Edição 20132014)". ${ }^{5}$ Através do PCS - Operações Coletivas, produziram-se, aproximadamente, 200 unidades habitacionais em Canavieiras-BA e Una-BA; pelo Programa Nacional de Habitação Rural (PNHR), participou da construção de, aproximadamente, outras 200 unidades habitacionais em Canavieiras-BA. Já pelo Programa de Subsídios à Habitação de Interesse Social (PSH), foram feitas reformas de mais de 700 moradias junto às comunidades de quilombolas, pescadores e marisqueiros da Bahia, e com moradores da Região de Caucaia do Alto e Atalaia, em Cotia-SP. Além disso, por meio de convênio com o Ministério da Pesca e Aquicultura, através de edital específico para contrataçâo de "Assessoria Técnica para Promoção de Habitação de Interesse Social e Desenvolvimento para pescadores", construíram-se 275 unidades habitacionais nos municípios de Ilha da Maré, Canavieira, Belmonte e Pedras de Una, na Bahia. Teve, portanto, uma atuação bastante capilarizada, composta por uma mescla de financiamentos envolvendo o Governo Federal, a Secretaria de Desenvolvimento Urbano do Estado da Bahia, a Caixa Econômica Federal, o Banco Induscal \& Partners (BI\&P), o Banco Paulista e o Banco Nordeste do Brasil. No âmbito do programa MCMV Entidades, a entidade desenvolveu empreendimentos na região do ABC paulista e um empreendimento em Maceió-AL, que somam aproximadamente 2000 unidades habitacionais. Para sua atuação, a Amova vale-se de uma rede de aproximadamente 100 outras entidades parceiras, com as quais estabelece relação desde a época das salas de alfabetização, constituída durante a década de 1990.

A inserção urbana do conjunto habitacional Sonho Meu, no município de Mauá-SP, cumpre, curiosamente, uma dupla condição: a de nova fronteira periférica e a de reafirmação de uma periferia consolidada. "Por fora", percorrendo o trecho sul do Rodoanel - novo eixo de conexão metropolitana, de estrutura perimetral -, apresenta uma paisagem curiosa: áreas preservadas de Mata Atlântica no entorno da Represa Billings, favelas e assentamentos precários autoconstruídos, áreas industriais e grandes vazios. Chegando a Mauá, já mais próximo da alça de acesso que se localiza num raio de $200 \mathrm{~m}$ do empreendimento, a paisagem se altera com a presença de concessionárias de automóveis, misturadas a grandes, monótonos e recentes conjuntos habitacionais de tipologia bastante verticalizada, sugerindo a abertura de uma frente importante para o capital imobiliário. "Por dentro", pela Avenida João Ramalho, que interliga os centros de Santo André e Mauá, rapidamente se chega ao Jardim Paranavaí, não sem cruzar uma paisagem que ganha outros traços, característicos de uma periferia consolidada: bairros periféricos, loteamentos populares, autoconstrução, outros pequenos conjuntos habitacionais em terrenos de topografia bastante acidentada, algumas ocupaçóes de favelas em áreas de risco, com alta declividade ou em fundos de vale, alta densidade construtiva, carência na oferta de espaços públicos.

Os conjuntos "João Cândido A" e "João Cândido B", construídos em regime de empreitada global, compreendem 384 unidades habitacionais organizadas em dois condomínios fechados, contendo 6 torres de 8 pavimentos e um centro comunitário/salão de festas cada. Localizados em Taboão da Serra-SP, os empreendimentos foram organizados por dois movimentos em consórcio: o MST Taboão da Serra (movimento de origem e atuação local) e o MTST - Movimento dos Trabalhadores Sem Terra.

O "maior apartamento do MCMV Entidades" e a mescla de tipologias de dois e três dormitórios, excepcionalizados pelo Ministério das Cidades a partir da pressão, sobretudo do MTST, poderiam, em princípio, serem lidos à luz das "virtuosidades" vinculadas principalmente à atuação de um movimento social que desponta na cena pública de lutas pela reforma urbana. Contudo, o processo revela a disputa tensionada por uma "marca". De um lado, por uma assessoria técnica (a Usina CTAH) comprometida com uma agenda ligada à autogestão habitacional - como meio de problematização dos 
temas relacionados ao direito à moradia e à cidade -, que inicia sua participação no processo com um plano de urbanização da área contratado pela Prefeitura local e discutido com a população organizada em ocupação, que previa soluçóes urbanísticas importantes baseadas em estudos relativos às demandas existentes e àquelas que seriam geradas, e que apontava para a construção de duas unidades escolares e conexóes viárias que dariam maior fluidez ao território. Em primeiro plano, o que se pretendia imprimir era uma crítica à naturalização das faixas de renda que produziam "faixas de direito à moradia" segmentadas, e trazer a ideia de que quanto menor a renda das famílias maior deveria ser o valor do investimento com a arquitetura, a infraestrutura urbana e a disposição de usos vinculados à necessidade habitacional dessa parcela da população. De outro lado, o governo estadual, através da sua companhia habitacional, apresenta projeto bastante problemático, mas que, sob a promessa de uma aprovação mais rápida, ganha a adesão dos movimentos.

Nesse ponto, a assessoria técnica assume outro papel no processo e, contratada agora pela construtora escolhida pelos movimentos, revisa o projeto da CDHU com a condição de que se reduzisse ao máximo o custo com os arrimos então previstos. Em contrapartida, a assessoria técnica negociou para que o valor reduzido não se revertesse integralmente em lucro para a construtora e sim em outras melhorias necessárias ao conjunto. As questóes se tratavam, em resumo: da adoção de grandes torres de pavimentos extensos monofuncionais, cuja implantação gerava os grandes muros de arrimo e orientava várias fachadas para o sul; da supressão da rua interna, que conectava o conjunto habitacional com o entorno, das escolas e do casarão que no projeto anterior cumpria importante papel simbólico e político; e da concepção espacial que envolvia a unidade habitacional e o pavimento tipo, com dormitórios mal arranjados e um corredor mal otimizado. Com a obra já em andamento, a assessoria técnica voltará à cena como fiscalizadora, contratada agora pelas entidades responsáveis pelo empreendimento, conforme medidas incorporadas às disposiçóes operacionais do programa ao longo do processo.
Por fim, destacam-se os empreendimentos "Florestan Fernandes e José Maria Amaral", que constituem único produto imobiliário de 396 unidades habitacionais organizadas em 16 torres de pavimentos variados (em média 12) e equipamento que se pretende de uso público, em construção desde 2010, por regime de administração direta no bairro Cidade Tiradentes, em São Paulo-SP.

A entidade organizadora, criada em 1987, no bojo da crescente luta pelo direito à cidade e à moradia, o Movimento de Trabalhadores Sem Terra Leste 1 (MTST Leste 1) - com vínculos com os movimentos nacionais União Nacional de Moradia Popular (UNMP) e Central de Moradias Populares $(\mathrm{CMP})$-, carrega em sua trajetória conquistas importantes envolvendo a produção de moradia popular através de procedimentos autogestionários, no atendimento a parte das famílias de baixa renda da Zona Leste de São Paulo. Os mutiróes com autogestão "União da Juta" e "Paulo Freire", iniciados na década de 1990 com assessoria técnica da Usina CTAH, em São Paulo, podem ser destacados, tanto em um campo amplo e consolidado de investigação em torno das experiências emblemáticas de produção habitacional "alternativa”, quanto na formação política e técnica que envolvem a gestão de processos como esse.

O terreno onde estão sendo construídos os empreendimentos se localiza a poucos minutos do Terminal Cidade Tiradentes. Conta com uma linha de ônibus - desde o terminal até a "porta" do conjunto "a Paulistinha", como é conhecida a linha Vila Paulista oferecida por meio de micro-ônibus -, em um percurso que conta com algumas poucas ruas estreitas e inclinadas, cortando um pedaço daquela região, bastante adensado e composto por um amontoado de edificaçóes autoconstruídas e irregulares, com forte presença de pequenos comércios e serviços, normalmente mesclados ao uso residencial. Tem como único vizinho um grande conjunto habitacional da CDHU com quem divide a única via de acesso e retorno disponível, a Rua Francisco José Alves.

A articulação com o proprietário da área foi feita diretamente pelo MTST Leste 1, a partir de 2008 (ainda no âmbito do PCS), através do grupo de trabalho criado na União dos Movimentos de 
Moradia de São Paulo (UMM-SP), com o objetivo de buscar terrenos livres e levantar preliminarmente a situação da área, suas características físicas e implicaçóes jurídicas, a partir das condicionalidades técnicas estabelecidas pelo programa.

A área era rural, e o movimento, através de sua assessoria jurídica, precisou negociar com o INCRA (Instituto Nacional de Colonização e Reforma Agrária) o lançamento de IPTU (Imposto Predial e Territorial Urbano) no terreno. Cientes de que esse processo não seria rápido, o MTST Leste 1, já no bojo do MCMV Entidades, recém-criado, e com a assessoria técnica da Ambiente Arquitetura, solicitou excepcionalização ao Ministério das Cidades, através da CEF, para contratar antecipadamente a compra do terreno e o pagamento da assessoria técnica, justificando e demonstrando que já tramitava no Incra o pedido de "tornar a área rural uma área urbanizada". Sobretudo pela excepcionalização requerida, mas também pelo fato da CEF não ter, até aquele momento, efetivado nenhum contrato dentro dessa modalidade, o que gerou, segundo a responsável técnica da Ambiente Arquitetura, uma série de "idas e vindas" de dúvidas entre a CEF e o Ministério, este processo demorou dois anos até se concretizar. Carregando a marca de ter realizado a primeira Compra Antecipada do programa - a partir da qual, possivelmente, algumas questóes operacionais técnicas tenham se dissolvido no interior da CEF -, o MTST Leste 1, através da sua assessoria técnica, deu-se início, em 2011, à etapa de aprovaçâo dos projetos na Prefeitura de São Paulo. Quanto à negociação com o Incra, só agora, no início de 2016, o lançamento do IPTU foi autorizado.

Além disso, a única rua de acesso ao terreno não era uma via pública oficial nos cadastros da Prefeitura, apesar, mas não surpreendentemente, de ser, na prática, a única via de acesso ao grande conjunto habitacional da CDHU, já mencionado. Novamente, através de sua assessoria jurídica, o MTST Leste 1 (agora Entidade Organizadora do conjunto habitacional) protocolou pedido para regularização da situação na Prefeitura, sem a qual o projeto arquitetônico e urbanístico não poderia ser aprovado. Nesse período, enquanto tramitava este processo, um primeiro grupo de famílias que já havia sido selecionado e organizado pelo movimento, passou a ocupar a área promovendo sua limpeza, corte de mato, primeiras reunióes do trabalho técnico social e outras atividades no local.

A regularização da rua levou aproximadamente um ano e meio para acontecer, e outros seis meses, ainda, para a aprovação do projeto. Em paralelo, corria também o licenciamento da área e a autorização para intervenção na APP (Área de Preservação Permanente), que se apresentava bastante alterada em relação à sua configuração original. Por essas questóes, o prazo de um ano para contratação da obra após a Compra Antecipada também precisou ser excepcionalizado junto ao Ministério das Cidades. O contrato da obra se efetivou, assim, em maio de 2013.

Da perspectiva investigativa que se pretende, determinados aspectos que atravessam os processos, brevemente apresentados, colocam questóes de análise importantes passíveis de serem destacadas e desenvolvidas quando lidas a partir dos dispositivos operacionais do programa destacados neste artigo.

Por esta chave interpretativa, destaca-se primeiramente o sistema de credenciamento e habilitação das entidades, cujo desenho operacional aparece em Portarias lançadas pelo Ministério das Cidades, prevendo um esquema de pontuação que determina o nível de qualificação das entidades, traduzido em sua área de abrangência e seus limites contratuais. Os pontos são determinados e distribuídos a partir da verificação da regularidade institucional, da avaliação da qualificação técnica e social, e da capacidade de mobilização da entidade.

Até abril de 2015, 851 entidades estavam habilitadas para participar do programa MCMV Entidades. No entanto, dessas, apenas 183 entidades $(21,5 \%)$ conseguiram viabilizar seus projetos: os 272 empreendimentos contratados neste período por meio de 387 operaçóes (considerando os contratos de Compra Antecipada e de obra). No cruzamento de informaçóes relativas às entidades que operam o MCMV Entidades - as 183 "vitoriosas" -, constata-se que a maioria apresenta uma amplitude de atividades formalizadas, nas quais a produção de moradia irá "se encaixar". Destacam-se as entidades que, em menor número, apresentam como natureza principal atividades relacionadas a outros temas - educação, religião, arte e cultura, 
produção e trabalho, que estarão vinculadas ao tema da habitação a partir de uma dimensão urbana, no âmbito dos direitos sociais. Essas entidades foram criadas, em uma quantidade bastante relevante $(46 ; 25 \%)$, na década de 1990 , muito provavelmente em função das políticas focalizadas, nas quais atuavam como "operadoras intermediárias"; mas a maioria foi criada na década de 2000 (118; $65 \%$ ), possivelmente em virtude de uma maior abertura do governo às formas participativas, com forte ampliação do número de políticas e programas sociais, e quantidade de recursos investidos. Em número menos expressivo, mas importante de ser ressaltado, aparecem as entidades criadas nas décadas de 1970 e 1980 (19; 10\%), no bojo da emergência dos movimentos sociais urbanos.

Tais entidades podem ou não apresentar vínculos, em menor ou maior grau, com os movimentos, e talvez por isso, se apresentam com origens e trajetórias difusas, atuando no programa a partir de estratégias distintas. Poderão se consorciar, mesmo quando suas perspectivas políticas e ideológicas atuam em direçôes opostas, de forma a se ajustarem ao desenho operacional do programa, para conformar grandes conjuntos habitacionais. Aos movimentos de moradia, sobretudo, cabe a reivindicação constante por mais recursos e por alteraçôes nas normativas do programa, procurando aproximá-las dos pressupostos construídos em torno da luta pela reforma urbana e da necessidade de desburocratização dos processos.

Isso posto, as entidades habilitadas articulam-se diretamente a um conjunto de estratégias e de modos de atuação que parecem deslizar de um campo mais reivindicativo para a operação do programa. Em geral, a produção dessas entidades aparecerá de forma bastante "profissionalizada”, e/ou estará vinculada aos contextos políticos locais. De modo similar, também atuarão lideranças de movimentos de moradia que, se de alguma forma continuarão a se mobilizar e pautar a agenda pública de luta pela reforma urbana e moradia digna, de outra, a "rede de contatos" - para além de uma rede de relaçóes construídas quando movimentos sociais e partidos políticos progressistas se constituíam e se consolidavam -, será muito frequentemente ativada pelas lideranças ou representantes das entidades organi- zadoras para "destravar" esse ou aquele processo, ou para se obter "excepcionalizaçóes" de toda ordem. E ainda, também será possível observar Prefeituras locais articuladas em torno de uma demanda própria e à "caça" de uma entidade qualquer habilitada para "fazer caber" um programa habitacional.

Em todos estes casos, o fato de um empreendimento estar constituído em torno de uma entidade que possui vinculaçáo com um movimento nacional de moradia, ou configurar-se ele próprio um movimento, não garante às famílias beneficiárias o acesso a um direito. A estrutura e organicidade das ações e formas de atuação que se estabelecem entre o movimento, o corpo dirigente da entidade e as suas bases, que podem ser mais ou menos aproximadas, mais ou menos mobilizadoras, os colocarão entre os direitos e a "clientela". Nessa linha interpretativa, pode-se se dizer que boa parte dos "alinhamentos" que se deram entre entidades e movimentos sociais, no âmbito do MCMV Entidades, aconteceram em virtude e para a operação do próprio programa. Nesses casos, a presença do movimento se restringe ao papel de buscar e encurtar caminhos, sobretudo pelos laços políticos que construiu nas últimas décadas. Portanto, importante dizer, serão esses mesmos laços que farão dos movimentos, representantes, de fato, das famílias organizadas em torno dos projetos, no tensionamento constante em relação ao desenho operacional e condicionalidades do programa.

Assim, entende-se que, na chave de leitura das "políticas de quantificação", seria possível problematizar a política pública enquanto "coisa administrável", que por um lado se ancora em técnicas modernas de gestão social (ou de gestão da pobreza) e, por outro, imputará às entidades e, inclusive aos movimentos de moradia, estratégias de atuação que as reduzirão a operadoras da política ${ }^{6}$, se "autoviabilizando" e se moldando aos dispositivos gerenciais e administráveis do programa. E ainda, participando, de modo bastante perverso, dos agenciamentos em torno da produção de "mercadorias políticas" (Misse, 2002), como aquilo que garantirá, ou se desdobrará das estratégias criadas para se driblar os sistemas de credenciamento e a viabilização de empreendimentos no programa.

Outro aspecto de análise importante e articulado às estratégias de atuação das entidades, reside no 
fato inexorável de que o programa abriu novos mercados. De um lado, envolvendo os poucos terrenos ainda disponíveis às entidades, aparecem empresas maiores ou pessoas jurídicas ligadas ao campo jurídico e contábil, intermediárias, adquirindo terrenos com recursos próprios, solucionando suas pendências e depois colocando-os novamente à disposição, a preços maiores. De outro, entidades que se configuram "braços associativos" de empresas vinculadas ao setor imobiliário, viabilizando "problemas habitacionais" desse ou daquele município, funcionando a partir de "filiais" instaladas dentro de escritórios de imobiliárias de âmbito local. Ou ainda, como vimos ser o caso da Amova, entidade organizadora do Conjunto Habitacional Sonho Meu, que reconfigura suas açóes quando percebe surgir novas "oportunidades para ampliar seus negócios".

Tecendo a trama, também os movimentos sociais que se configuraram entidades organizadoras do empreendimento João Cândido A e B, o MST Taboão e o MTST - de agendas ideológicas publicamente distintas, mas de estrutura e forma de atuação bastante semelhantes -, alinhando-se, a fim de darem respostas rápidas às suas bases, inclusive abrindo máo de alguns pressupostos construídos de forma mais ou menos coletiva para dispor de mais moradias, aproximaram-se de uma lógica de mercado que visa obter lucros com a otimização do processo construtivo (no caso, a aplicação das fôrmas em mais um ou dois edifícios habitacionais em substituição aos equipamentos educacionais previstos no projeto).

Já nos conjuntos Florestan Fernandes e José Maria Amaral, a experiência obtida por determinados membros da entidade/movimento, outrora beneficiários de programas anteriores, os levaram a ocupar "cargos" administrativos e decisórios na gestão dos processos que envolveram a construção dos conjuntos mencionados, e a exercer importante papel político na difusão e consolidação da presença e atuação do movimento, no território onde os empreendimentos foram construídos. Atuaram, por meio da abertura de novos grupos de associados, visando outros empreendimentos na região, também na garantia de acesso dos moradores em instâncias participativas locais envolvendo o Estado e a implementação de políticas no território.
Da perspectiva de implementação de um processo que envolvesse a autogestáo como princípio e categoria mais ampla, vale destacar o vínculo da entidade/movimento com Assessorias Técnicas, que nos conjuntos Florestan Fernandes e José Maria Amaral ocorreu junto à Ambiente Arquitetura, desde os procedimentos relacionados à legalização e compra do terreno, às discussóes em torno do projeto de arquitetura das edificaçóes - que transitaram entre a escala da unidade habitacional à implantação ou inserção dos empreendimentos no território -, e à fase de construção e ocupação das moradias propriamente ditas. Nesse ponto, parece importante destacar que, a partir deste vínculo, para além das comissóes participativas previstas pelas normativas do programa, organizaram-se outras dezoito comissóes temáticas: de meio ambiente, de compras, de pontuação, entre outras, onde se dividem igualmente e integralmente as famílias que compóem os dois conjuntos.

Os casos sugerem que são as "oportunidades" decorrentes das articulaçóes, que essas entidades estabelecerão com outros agentes e em localidades distintas, que determinarão o desenho operacional ao qual estarão submetidos os projetos e os processos.

Do ponto de vista do sistema de credenciamento das famílias beneficiárias, a "profissionalização" necessária para se "operar o programa”, que sugere um conjunto de mutaçôes, modulaçóes e reconfiguraçôes dos movimentos sociais, mas numa mesma direção, aponta para a "reconversão de associaçóes em entrepostos avançados do terceiro setor", a partir das quais é possível apreender novos "dispositivos de mobilização permanente para a concorrência na execução de projetos, na captação de financiamentos, e nos prêmios que dão visibilidade às iniciativas" (Magalhães, 2011, p. 259). Esse "mercado da cidadania" (Abílio, 2011) - no qual se entrecruzam entidades privadas, interesses privados, parcerias públicas, todos providos pela delimitação e pela focalização da pobreza -, transforma em público-alvo de programas, projetos e políticas sociais, aqueles que vivem a "viração" (Silva, 2011) e a precariedade do cotidiano da periferia, num contexto marcado por estratégias político-financeiras que fizeram ascender socialmente e engrossar a agora considerada "classe C". Esta, por sua vez, foi 
descoberta como um nicho promissor e lucrativo para o mercado imobiliário e, mais do que isso, importante elemento nos processos de financeirizaçáo e monetarização das políticas sociais.

Esses deslizamentos, seus pressupostos e as formas que se implementam para operação deste programa se desdobram pelas condiçóes de vida, pelas perspectivas e fluxos de trajetórias de moradia na cidade, e por um conjunto de programas e políticas sociais combinadas, que vão das políticas de transferência de renda aos programas de incentivo cultural, dos programas de saúde aos de moradia, sobrepostos a partir dos desenhos e normativas de cada programa, de suas proposiçóes, condicionalidades e dispositivos que se estendem até a produçâo e gestão de públicos-alvo (Rizek, 2015).

Diante desse quadro de constituiçáo de um "governo moral dos pobres" (Lautier, 2009), que ganha operadores e modos de operação, localizam-se zonas de indiferenciação (Rizek, 2012) entre o Estado e o que acabou sendo denominado como sociedade civil, no cruzamento da constituição da demanda de cada programa e dos protagonismos e formas de participação, requeridos para que o "bom beneficiário"7 acabe contemplado, cumprindo as condicionalidades de cada benefício.

No caso do conjunto habitacional "Sonho Meu”, organizado pela Amova, o grupo de famílias que compóem a demanda não apresentava tradição na luta pela reforma urbana. São famílias de baixa renda, que precisavam de moradia, mas a sua adesão a essa entidade e a esse programa em específico é algo, de certa forma, fortuito: por indicação de uma das entidades parceiras da Amova, cujos critérios de seleção são absolutamente nebulosos; ou por mero acaso. $\mathrm{O}$ ingresso à entidade é vinculado ao projeto habitacional, ou seja, eles entram na entidade como beneficiários e tão logo recebam suas moradias e quitem suas pendências, este vínculo será automaticamente encerrado. Os raros casos de participação comunitária que permeiam as trajetórias mais se relacionam com trabalhos voluntários ligados a açóes assistenciais e religiosas, do que propriamente com as lutas sociais.

Já nos conjuntos João Cândido A e B, dados os dois pesos - do tamanho do MTST e dos trânsitos locais da principal liderança do MST Taboão
-, os dois movimentos fizeram um acordo ficando cada um responsável por um conjunto habitacional e pela organização da "sua" própria demanda.

Aquilo que se configurou "marca", pelo menos para as lideranças dos movimentos - o tamanho dos apartamentos -, acabou virando um ponto de fricção bastante representativo da pouca participação dos moradores no processo e da estrutura bastante verticalizada presente na forma de atuação das entidades/movimentos, ainda que, como origem, tal demanda tenha sido organizada a partir de duas ocupaçôes: a primeira, Ocupação "Chico Mendes”, iniciada em 2005, no próprio município de Taboão da Serra; e a segunda, Ocupação "João Cândido", iniciada em 2007, em Itapecerica da Serra.

Do ponto de vista da relação da demanda com sua própria moradia e com o processo que envolveu sua construçáo, parece relevante destacar que em um conjunto, a síndica eleita, de grande proximidade à liderança do MST Taboão, continuou presente e liderando o processo de apropriação no conjunto, chamando a atenção dos moradores em relação às regras de uso dos espaços de convivência, recebendo queixas de alguns moradores, e conduzindo as "melhorias" dos espaços de convivência.

Ao contrário, no conjunto habitacional do MTST, a atenção estava toda voltada para as adaptaçóes e reformas internas às unidades habitacionais. Membros do MTST que participaram mais ativamente das questôes relacionadas à construção, por terem sido contratados pela construtora para trabalhar no canteiro de obras, formaram lideranças neste processo, claramente reconhecidas, e não sem conflitos, pelo conjunto dos demais moradores como referências para o encaminhamento de assuntos diversos pertinentes ao condomínio (um deles, inclusive, tornou-se síndico do condomínio). Contudo, diante da expertise que ganharam sobre o sistema construtivo, não tiveram problema algum em formalizar uma pequena empresa especializada nas adaptaçôes e melhorias das unidades habitacionais de seus vizinhos: adaptação do banheiro, cujo layout respeita as normas de acessibilidade, mas que em termos de uso são pouco práticas; instalação de banheira de hidromassagem, aproveitando as grandes dimensóes do banheiro adaptado; extensão do ponto de TV para os dormitórios; aplicação 
de forro de gesso para condução da fiação elétrica até os dormitórios, para esconder o acabamento "chapiscado" aplicado no teto pela construtora para esconder os defeitos da fôrma, e para dar novas possibilidades de iluminação para os ambientes; adaptaçôes na cozinha - em geral, alterando a posição da geladeira -, e incorporando um balcáo na divisão com a sala.

Tais interaçóes apontam para o fato de que uma construção política ou politizante não parece ter se desdobrado dos processos que envolveram estes conjuntos habitacionais, e, pelo contrário, ficaram bastante submetidos a um conjunto de práticas incorporadas a uma miríade de mercados que envolvem a produção habitacional recente, inclusive sugerindo ressignificaçóes importantes ou novas modulaçōes a determinadas práticas mais associadas a processos reivindicativos.

Nos conjuntos Florestan Fernandes e José Maria Amaral, a demanda era toda originária do movimento. Os grupos de origem sáo a porta de entrada no movimento de moradia e seus núcleos de base. Eles estão organizados em diversos bairros da cidade e se agrupam regionalmente em função do movimento do qual participam. Tais grupos, coordenados por lideranças populares, muitas vezes amparados por Comunidades Eclesiais de Base e Pastorais da Igreja Católica, fazem suas reunióes em paróquias e salóes comunitários. As famílias entram nesses grupos, convidadas por amigos, parentes, vizinhos, ou mesmo após serem informadas da sua existência na missa que frequentam. São famílias, em geral, com renda inferior a dois mil reais, que aguardam a moradia há anos na fila da $\mathrm{COHAB}$ (Companhia Metropolitana de Habitação da Prefeitura de Sáo Paulo) e CDHU (Companhia de Desenvolvimentos Habitacional e Urbano do Estado de São Paulo), muitos em situaçáo crítica de moradia: risco de despejo, não suportam mais o aluguel, não querem ou não podem mais depender de favores, moram em situação de superlotação habitacional, em cortiços, favelas, etc.

A formação de base nos grupos de origem é diversificada. Discute-se a política de habitação, apresenta-se a bandeira de luta do mutirão com autogestão e como é administrada uma obra do movimento. Além das conversas, são feitas ativi- dades mais práticas: visitas a mutiróes em obras ou concluídos; festas, rifas e bingos para arrecadar recursos; passeatas e manifestaçōes, até ocupaçóes de terra e imóveis, algumas delas com permanência prolongada enquanto acontecem negociaçóes com o governo. Há um enorme aprendizado do que está em disputa. O conflito é visível, a luta por moradia aparece como algo concreto.

Contudo, para uma parcela significativa da base, é a pontuação que as famílias recebem por atividade o que motiva a presença no local. São os pontos que garantem o ingresso nos novos projetos: as famílias de cada grupo de origem com mais pontos acumulados (por presença em reunióes, atos, ocupaçôes e pela contribuição mensal ao movimento) poderão escolher primeiro em qual projeto habitacional ingressar. O sistema de pontos é, assim, um instrumento de aferição da presença e participaçáo, que mede o empenho e o mérito das famílias que serão primeiramente atendidas.

Quando as famílias são transferidas para as Associações de Construção em formação, inicia-se um novo ciclo de aprendizado. As Associaçóes são constituídas no momento em que o movimento conquista, dentro de um determinado programa vigente, um terreno ou uma linha de financiamento. Elas têm estatuto social e figura jurídica para assinatura de convênios com o poder público.

Igualmente relevante parece ser o fato de que boa parte da demanda desses dois últimos conjuntos mencionados já havia experimentado, a partir de uma geração anterior formada por seus pais ou avós, o trabalho em mutirão e autogestão como procedimento de gestáo compartilhada de todo o processo de produção da moradia, que se desdobrava em um determinado compromisso com as lutas sociais que envolvem o território periférico - ainda que isso náo tenha se revelado em uma contrariedade, por exemplo, com o novo local de moradia, bastante distante do anterior e de um conjunto de relaçôes já estabelecidas na e com a cidade.

Por fim, no âmbito dos dispositivos operacionais do programa MCMV Entidades, vale ressaltar as contrapartidas que comporão o desenho do financiamento, que tanto envolvem prefeituras e governos estaduais, e também os Agentes Fomentadores, que participam com o apoio técnico, na 
intermediação ou atuação direta na viabilização da terra, na forma de aportes financeiros, na execução direta de etapas de obra, e/ou no estabelecimento de convênios a partir do qual se comprometem a tornar as aprovaçóes e licenciamentos mais ágeis, podendo indicar demanda através de seus próprios cadastros. Cada uma dessas possibilidades é negociada individualmente, e são "conquistas" que dependem de cada contexto, da articulação das entidades, da proximidade ou da pressão dos movimentos de luta por moradia. E ainda podem somar-se a essas formas de contrapartida, aquelas fornecidas pelas entidades organizadoras através das famílias que compóem o grupo de demanda, pelas quais se revelam as excepcionalizaçóes que parecem sustentar o programa.

Se, por um lado, será esse o mecanismo que garantirá aberturas do ponto de vista arquitetônico e construtivo que resultarão em produtos melhores, por outro, será por uma somatória de exceçóes que o programa minimamente "rodará". Essas excepcionalizaçôes irâo se referir, principalmente, aos limites operacionais: percentual do valor do terreno em relação ao valor total de financiamento maior que os $15 \%$ previstos na norma; número de unidades habitacionais por empreendimento maior do que o máximo permitido; prazos para contratação da obra, uma vez realizada a Compra Antecipada, e da realização da obra propriamente dita, entre outras. Inscrevem-se, portanto, em uma dimensão privada e, dessa perspectiva, a própria ideia de viabilidade precisa ser problematizada, uma vez que é formulada e se pauta a partir do mercado, ou da moradia como mercadoria.

As excepcionalizaçóes, em geral, serão transformadas em contrapartidas financeiras e físicas (de trabalho em mutirão) bastante altas e custarão diretamente às famílias beneficiárias (como, por exemplo, uma entrada que garanta a compra do terreno junto ao proprietário, antes que se efetive a contratação, e que aparecerá nas planilhas como uma contrapartida financeira). Outras contrapartidas serão negociadas, preliminarmente e ao longo do processo de construção do empreendimento, e essas nem comporão as planilhas apresentadas à CEF que, portanto, nem tomará conhecimento das mesmas. Serão articuladas exclusivamente entre as entidades e as famílias beneficiárias, com mais ou menos participação das assessorias técnicas e/ou construtoras, e corresponderão a itens, ou quantidades, não previstos pelo programa, ou suprimidos das planilhas orçamentárias para "fazer a conta fechar", como, por exemplo: sob a égide do medo a contratação de "segurança 24 horas" para o canteiro de obras, o sistema de monitoramento de todas as áreas coletivas, ou o esforço pessoal no revezamento de vigília "24 horas" no canteiro de obras.

\section{Conclusão}

O presente artigo reuniu aspectos e questóes que buscaram aproximar a produção empreendida no âmbito do MCMV Entidades à dimensão operacional que envolve o processo de empresariamento e financeirização da moradia (e da cidade), observado no Brasil principalmente a partir de meados da década de 2000, quando se inscreve com papel bastante importante, o pacote-programa habitacional Minha Casa Minha Vida. Trabalha-se a ideia de que o MCMV Entidades, sob alguns aspectos, ativa e se submete um conjunto de circuitos e práticas de mercado onde a dimensão econômica se aprofunda, não tanto no sentido dos ganhos diretos e financeiros obtidos com essa produção, mas pela reconfiguração dos movimentos de moradia e a redução de uma agenda ampla relacionada à reforma urbana à operação do programa.

Desta perspectiva, o MCMV Entidades coloca-se "entre os direitos, as urgências e os negócios" e, talvez por essa lente, pudesse ser lido um conjunto de deslizamentos e ressignificaçóes no bojo das lutas sociais recentes.

$\mathrm{Na}$ aproximação sistemática com as famílias beneficiárias que compóem os diferentes grupos de demanda dos conjuntos que estudamos, as urgências são flagrantes - entre as quais, a moradia. São situações transitórias, provisórias, principalmente relacionadas às suas trajetórias de moradia e trabalho que, imbricadas, ditarão ritmo e tempos de sobrevivência. Atravessando esses tempos, as situaçôes pessoais e familiares, marcadas por violências de muitos tipos, vez ou outra, mudam o curso e os sentidos. $\mathrm{O}$ alívio das carências enseja situações 
bastante diversas, indica perspectivas de conquista de direitos voltados à redução das desigualdades sociais, expressa melhoria das condiçóes de vida privada, sem necessariamente sinalizar para um maior envolvimento com as questóes públicas e políticas.

A disputa por terrenos para a qual as entidades e os movimentos de moradia são empurrados pelo desenho operacional do próprio programa, é outro aspecto bastante relevante e talvez onde mais se expresse a noção da cidade como negócio. Mas a essa disputa somam-se outras práticas de mercado estimuladas ou aprofundadas pelo programa, com implicaçóes diretas e indiretas no encolhimento e reconfiguração da atuação dos movimentos sociais urbanos. Ganham espaço as entidades "mais profissionais", e que, por isso mesmo, são verdadeiras "máquinas de produzir moradias". Distantes da agenda de lutas e reivindicaçóes, inclusive aquela reduzida que focaliza de modo bastante específico a operacionalidade do programa MCMV Entidades, os movimentos de moradia, por um lado, se aproveitarão das conquistas, ainda que pontuais, resultantes desse processo e, por outro, em suas articulaçóes e formas de atuação, lançarão mão de novas estratégias inscritas em um universo de dimensáo privada e em uma lógica de incorporação no e pelo mercado.

Contudo, de um modo geral, talvez seja ainda possível apontar para a natureza dessas práticas como síntese de longos processos: a "confluência perversa" (Dagnino, 2004) que imputou novas formas de relaçōes entre Estado e sociedade brasileira no contexto de democratizaçáo, mediada por entidades difusas; o uso de recursos oriundos de fundos públicos financiando novas formas de intervenção do Estado e do capital no espaço urbano; as práticas que envolvem a produção de moradias imbricadas a práticas de mercado que reduzem seu valor de uso e incitam a construção de mercadorias políticas; a autogestão como procedimento ou possibilidade de democratização do desenho, de formação política, mas também de gestão autônoma da escassez de recursos, assim como os expedientes que permitem, caso a caso, que ela seja driblada; projetos arquitetônicos e urbanísticos, em geral padronizados e simplificados, rebaixados ao nível das carências já vivenciadas, produzindo os novos locais de moradia; a fragmentação dos territórios urbanos peri- féricos, a partir das piores áreas ainda disponíveis, reforçadas de um lado, pelo porte, contiguidade ou proximidade, e pelas formas arquitetônicas carimbadas e "resolvidas" em condomínios fechados, e de outro, pelas fricçóes imputadas pelos processos, tal como se desenham nesses espaços.

Todos esses elementos podem conduzir à riqueza de dimensóes, de sentidos, de suas transformações, em uma "síntese negativa", diante da urgência da sobrevivência, diante da calamidade da necessidade e diante de formas de articulação que apontam para novos modos de administraçáo e de controle dessas populaçóes e de seus movimentos e articulaçóes. Já da perspectiva da análise sobre as práticas e a agenda dos movimentos de moradia, parece importante destacar o lugar assumido pelos mesmos no contexto político recente, frente ao que parecia ser o fim da era Lula/Dilma: na reivindicação de manutenção do programa, fortemente ameaçado, dão conta da organização de determinado campo pela aglutinação de formas múltiplas associativas e de movimentos sociais distintos, bem como por parte da Academia e Assessorias Técnicas pela reivindicação do programa frente às novas e mais restritivas condiçóes de operacionalidade e cortes financeiros significativos e, de modo mais amplo, na retomada de uma agenda pública em torno da reforma urbana.

\section{Notas}

1 Integram o MCMV, além da "Construtoras", as modalidades Entidades, PNHR (rural) e Sub 50 (municípios com menos de 50 mil habitantes), incluídos sob intensas reivindicaçóes e representando menos de $10 \%$ das metas físicas e financeiras em seu lançamento.

2 Até 2015, o MCMV Entidades participou com 1,3\% dos recursos e $1,15 \%$ das moradias contratadas (UH). Nas Fases 1 e 2, as metas físicas estabelecidas eram de produção de 30 mil e $60 \mathrm{mil} \mathrm{UH}$, respectivamente, ou $3 \%$ do previsto para as modalidades de atendimento à Faixa 1 (Camargo, 2016).

3 Uma vez que estavam superadas as outras formas de organização popular, principalmente as sindicais ou outras relacionadas ao trabalho, sobretudo pelas transformaçóes recentes nas redes de produção que ficaram complexas e muito diversificadas. 
4 Lautier, 2009, tradução de Cibele Rizek (in mimeo).

5 Criado em 1999, com base no modelo do programa das Naçôes Unidas "Best Practices and Local Leadership Programme", que coloca em prática a Agenda Habitat, documento que reúne diretrizes para criar padróes de vida sustentáveis em assentamentos.

6 Ou de movimentos de moradia e entidades distintas, embaralhados nesse novo campo associativo, como o "Estado nas margens" (Das \& Poole, 2004; Telles, 2010).

7 Para Lautier (2009), o "bom pobre" aceita a inquirição sobre sua renda e admite facilmente que deve ser reeducado. É franco e humilde. O mau pobre considera a ajuda assistencial como uma obrigação e recusa que possa haver contrapartidas a essa ajuda.

\section{BIBLIOGRAFIA}

ABÍLIO, Ludmila Costhek. (2011), "A gestão do social e o mercado da cidadania”, in R. Cabanes et al. (orgs.), Saidas de emergência: ganharl perder a vida na periferia de São Paulo, São Paulo, Boitempo, 297-316.

BARDET, Fabrice. (2015), From statistics to accountings: How Desrosières perspective suggests to change the focus on the figures that rule the world. ENTPE. Disponível em http://www.entpe. fr, consultado em 15/08/2016.

CAMARGO, Camila. (2013), "Novas formas associativas na produção recente de moradia social no Brasil". Revista Brasileira de Estudos Urbanos e Regionais, 15 (2): 77-88.

CAMARGO, Camila. (2016), Minha Casa Minha Vida Entidades: entre os direitos, as urgências e os negócios. Tese de Doutorado. Instituto de Arquitetura e Urbanismo (IAU USP), Universidade de São Paulo, São Carlos-SP.

FIX, Mariana. (2007), São Paulo, cidade global: fundamentos financeiros de uma miragem. São Paulo, Boitempo.

DAGNINO, Evelina. (2004), Construção democrática, neoliberalismo e participação: os dilemas da confluência perversa. Politica \& Sociedade, 5: 139-164.

DAS, Veena \& POOLE, Deborah. (2004), Anthropology in the Margins of the State. Santa Fé, Ox- ford, School of American Research Press/James Currey.

HARVEY, David. (2014), Cidades rebeldes: do direito à cidade à revolução urbana. São Paulo, Martins Fontes.

LAUTIER, Bruno. (2009), "Gouvernement moral des pauvres et dépolitisation des politiques publiques en Amérique latine", in N. Borgeaud-Garciandía et al. Penser le politique en Amérique latine: la recréation des espaces et des formes du politique, Paris, Karthala, 19-36.

MAGALHÂES, José César. (2011), "As entidades sociais e o surgimento de uma gestão concorrencial de engajamento cívico", in R. Cabanes et al. (orgs.), Saidas de emergência: ganhar/perder a vida na periferia de São Paulo, São Paulo, Boitempo, 257-278.

MARANHÃO, Tatiana. (2010), Governança mundial e pobreza: do Consenso de Washington ao consenso das oportunidades. Tese de Doutorado, Universidade de São Paulo, São Paulo.

MISSE, Michel. (2002), Rio como um bazar, a conversáo da ilegalidade em mercadoria politica. Insight Inteligência, 3 (5): 12-16.

PAOLI, Maria Célia. (2007), "O mundo do indistinto: sobre gestão, violência e política”, in F. Oliveira, \& C. S. Rizek (orgs.), A era da indeterminação, São Paulo, Boitempo, 221-256.

PAULANI, Leda (2017), "A experiência brasileira entre 2003 e 2014: Neodesenvolvimentismo?" Cadernos de Desenvolvimento, 12 (20): 135155.

RIZEK, Cibele Saliba; (2012), “Trabalho, moradia e cidade: zonas de indiferenciação?", Revista Brasileira de Ciências Sociais, 27 (78): 41-48.

RIZEK, Cibele Saliba. (2015), "Gestão da Cidade/ Gestão Diferencial da Vida/Confinamento e Moralização", in P. Jacques, \& F. Britto (orgs.), Experiências metodológicas para compreensão da complexidade da cidade contemporânea: III. Alteridade, imagem, etnografia. Salvador, EDUFBA, 28-51.

RIZEK, Cibele Saliba; SANTO AMORE, Caio, \& CAMARGO, Camila. (2014), "Política Social, Gestão e Negócio na produção das cidades: o programa Minha Casa Minha Vida Entidades”. Caderno CRH, 27 (72): 531-546. 
RIZEK, Cibele Saliba; SANTO AMORE, Caio, \& CAMARGO, Camila. (2015), "Política Habitacional e Políticas Sociais: urgências, direitos e negócios", in A. F. Carlos, D. Volochko, \& I. Alvarez (orgs.), A cidade como negócio, São Paulo, Contexto, 165-184.

ROLNIK, Raquel. (2015), Guerra dos lugares: a colonização da terra e da moradia na era das finanças. São Paulo, Boitempo.

SHIMBO, Lúcia (2016), "Sobre os capitais que produzem habitaçóes no Brasil", Dossiê Habitação no Brasil, Cebrap, 35 (02): 119-133.

SANFELICI, Daniel. (2013), A metrópole sob o ritmo das finanças: implicaçóes socioespaciais da expansão imobiliária no Brasil. Tese de Doutorado. Universidade de São Paulo, São Paulo.

SILVA, Carlos Freire. (2011), "Viração: o comércio informal dos vendedores ambulantes", in R. Cabanes et al. (orgs), Saídas de Emergência: ganhar/perder a vida na periferia de São Paulo, São Paulo, Boitempo, 57-74.

TARROW, Sidney. (2009), Poder em movimento: movimentos sociais e confronto politico, Rio de Janeiro, Vozes.

TATAGIBA, Luciana \& TEIXEIRA, Ana. (2014), "Os efeitos do movimento de moradia sobre as políticas públicas”. Anais Eletrônicos do IX Encontro da Associação Brasileira de Ciência Politica, 1: 1-30.

TELLES, Vera. (2010), "Nas dobras do legal e ilegal: ilegalismos e jogos de poder nas tramas da cidade”. Dilemas - Revista de estudos de conflito e controle social, v. 2, n. 5-6: 97-126. 


\section{MINHA CASA MINHA VIDA - ENTIDADES: NOVOS ARRANJOS PARA A OPERAÇÃO DA POLÍTICA HABITACIONAL NO BRASIL}

\section{Camila Moreno de Camargo}

Palavras-chave: Políticas habitacionais; Movimentos sociais; Financeirizaçáo

Algumas análises recentes sobre a modalidade Entidades do programa Minha Casa Minha Vida sugerem que as práticas de mercado que o programa ativa e aos quais também se submete, implicam em deslizamentos e um conjunto de ressignificaçóes em direção à operação do programa. A partir de empreendimentos localizados na Região Metropolitana de São Paulo, destacam-se aspectos relacionados a dispositivos operacionais do programa, quais sejam: o sistema de credenciamento e habilitação das entidades organizadoras, o sistema de credenciamento das famílias beneficiárias e o sistema de contrapartidas, por onde se entrevê que apesar de serem modulados a partir dos territórios em que se inscrevem, as questóes localizadas na articulação entre os níveis de concepção do programa, dos agenciamentos em torno de sua operacionalização, e de sua implementação no território, apontam para formulaçóes mais amplas com fortes nexos com o contexto de operacionalização e financeirização de políticas públicas.

\section{MINHA CASA MINHA VIDA- ENTITIES: NEW ARRANGMENTS FOR THE OPERATIONS OF BRAZILIAN HOUSING POLICY}

\section{Camila Moreno de Camargo}

Keywords: Housing policies; Social movements; Financialization

Recent analyzes on the modality "Entities" of the Minha Casa Minha Vida program suggest that the market practices that the program activates and to which it is submitted imply changes and a set of reframings relative to the program operation. Observing projects located in the Metropolitan Region of São Paulo, there are specific aspects of the program's operational devices that stand out: the system of accreditation and qualification of the organizing entities, the system of accreditation of the beneficiary families and the system of counterparts. These aspects allow us to see that, despite being modulates from the territories in which they are inserted, the issues located in the articulation between the levels of conception of the program, the agencies around its operationalization, and its implementation in the territory, designate broader formulations with strong links with the context of operationalization and financialization of public policies.

\section{MINHA CASA, MINHA VIDA - INSTITUTIONS: NOUVEAUX ARRANGEMENTS POUR L'OPÉRATION DE LA POLITIQUE DU LOGEMENT AU BRÉSIL}

\section{Camila Moreno de Camargo}

Mots-clés: Politiques de logement; Mouvements sociaux; Finances

Certaines analyses récentes sur les modalités des institutions du programme Minha Casa, Minha Vida (Mon logement, ma vie) suggèrent que les pratiques de marché que le programme active et auxquelles, également, il se soumet, impliquent en des dérapages et en un ensemble de nouvelles significations relatives à sa mise en place. Ầ partir de projets situés dans la région métropolitaine de São Paulo, nous mettons l'accent sur les aspects liés aux dispositifs opérationnels du programme, qui sont : le système d'accréditation et de qualification des entités organisatrices, le système d'accréditation des familles bénéficiaires et le système de contreparties, par lesquels il est possible de constater que, bien qu'ils soient modulés à partir des territoires dans lesquels ils sont inscrits, les questions situées dans l'articulation entre les niveaux de conception du programme, les organismes autour de son opérationnalisation et sa mise en œuvre sur le territoire, indiquent des formulations plus larges ayant des liens étroits avec le contexte de l'opérationnalisation et du financement des politiques publiques. 